Светлана Бодрунова, Анна Смолярова,

Вера Ачкасова, Иван Блеканов

\title{
КТО ВИНОВАТ? ПАТТЕРНЫ ПРИСВОЕНИЯ ВИНЫ И ОТВЕТСТВЕННОСТИ В СЕТЕВЫХ ДИСКУССИЯХ ОБ ИММИГРАНТАХ В РОССИИ И ГЕРМАНИИ
}

\begin{abstract}
Конфликты с участием переселенцев с «глобального Юга» и их обсуждение в медиа и социальных сетях стали чертой современной публичной сферы в Европе и России. Сетевые дискуссии способны играть роль групп давления в формировании повестки обсуждения миграции и принятия политических решений, актуализируя как конфликтные, так и консенсусные общественные настроения. Важно знать, существуют ли закономерности в том, кого пользователи сети (в том числе институциональные) видят как виновников конфликтов и от кого ожидают его разрешения. Мы рассматриваем четыре конфликтные дискуссии в Твиттере в России и Германии 2013-2016 гг. и оцениваем связь статуса пользователя с паттернами присвоения вины и ответственности, а также сопоставляем дискурсивные стратегии обвинения в двух странах. Методология исследования включает веб-краулинг по заданному словарю, экспертную оценку аккаунтов пользователей, ручное кодирование твитов и описательную статистику. Итоги исследования говорят о том, что в целом обвинение направлено в первую
\end{abstract}

Светлана Сергеевна Бодрунова - д.полит.н., профессор, Высшая школа журналистики и массовых коммуникаций, Санкт-Петербургский государственный университет, СанктПетербург, Россия. Электронная почта: s.bodrunova@spbu.ru

Анна Сергеевна Смолярова - к.полит..н. доцент, Высшая школа журналистики и массовых коммуникаций, Санкт-Петербургский государственный университет, Санкт-Петербург, Россия. Электронная почта: a.smoliarova@spbu.ru

Вера Алексеевна Ачкасова - д.полит.н., профессор, Высшая школа журналистики и массовых коммуникаций, Санкт-Петербургский государственный университет, СанктПетербург, Россия. Электронная почта: v.achkasova@spbu.ru

Иван Станиславович Блеканов - к.т.н., доцент, факультет прикладной математики - процессов управления, Санкт-Петербургский государственный университет, Санкт-Петербург, Россия. Электронная почта: i.blekanov@spbu.ru 
очередь против трех групп: региональных властей, национального лидера/ правительства и иммигрантов; разрешения конфликтов пользователи ждут от федеральных властей, ответственных за изменение иммиграционной политики. Но если в Германии очевиден политический разлом между правыми (пронационалистическими) и левыми (феминистскими) стратегиями поиска виноватых, частично компенсируемые нейтральным медиадискурсом, то в российском Твиттере доминирует обвинение и власти, и иммигрантов, а также распространены сниженные ожидания мирной политической разрядки межэтнической напряженности.

Ключевые слова: иммигранты, межнациональный конфликт, Твиттер, Германия, Россия

DOI: 10.17323/727-0634-2018-16-4-627-644

Конфликты с участием переселенцев по оси «север - юг» и их обсуждение в медиа и социальных сетях стали чертой современной публичной сферы в Европе и России. По данным ООН (United Nations 2013), Россия и Германия остаются одними из основных мест привлечения глобальных миграционных потоков. Это порождает в двух странах напряженность, заметную по росту числа крупных и малых конфликтов на межэтнической почве, а также по поляризации и борьбе в сфере регулирования миграции.

Сетевые дискуссии могут играть роль групп давления в формировании повестки дня и миграционной политики (Trottier, Fuchs 2014), но непрямым образом (Tufekci 2014). Дискуссии актуализируют конфликтные настроения, демонстрируя социальную поляризацию, которая может не совпадать с партийным распределением (Bodrunova et al. 2019), и, несмотря на ограничения исследований виртуального пространства с точки зрения социальной репрезентации (Daniels 2013), изучение сетевого контента способно выявить аттитюды, в т.ч. описать участников конфликта и отношение к ним.

Важную роль и в разрешении конфликтов, и в обсуждении миграции играет то, какие акторы признаются виновниками конфликта и на кого возлагается ответственность за выход из кризисной ситуации. Остается вопросом, есть ли в присвоении вины и ответственности кросс-культурные закономерности или же они являются национально-обусловленными. Для выявления паттернов вины и ответственности мы изучили дискуссии в Твиттере о четырех сходных конфликтах в России и Германии 2013-2016 гг. Это конфликты с насильственным триггером, в которых межличностный конфликт «вскрывает» групповую напряженность между «принимающим сообществом» и иммигрантами. В разных политических контекстах и медиасистемах паттерны присвоения вины и ответственности различаются, несмотря на схожесть иных аспектов конфликта. При этом исследований, где они бы сравнивались, нет, а русскоязычные сравнительные исследования дискурса о мигрантах в России и Германии публикуются реже, чем раз в десять лет (Малахов 2004; Свинкина 2016; Диденко 2017). Сравнительные 
работы политических лингвистов не задействуют либо российский (Нестерова, Бурова 2016), либо немецкий (Калыгина 2009) контексты. Игнорирование российского контекста также характерно для немецких исследований, за исключением редких случаев (Pöttker 2006). Наше исследование призвано частично восполнить этот пробел. Ниже мы оцениваем связь статуса пользователя с паттернами присвоения вины и ответственности, а также описываем направленность вины и ответственности в Твиттере двух стран.

\section{Социальные медиа и конфликт: присвоение вины и ответственности}

Сегодня ученые исследуют роль новых механизмов общественной дискуссии в политике, в т.ч. роль социальных медиа как в разрешении кризисов (Patrona 2018), так и в нагнетании конфликтности (Heverin, Zach 2012). При этом современные работы менее оптимистичны, чем ранее: они указывают на «нормализацию» пользования социальными медиа со стороны властных акторов (Lasorsa et al. 2012) и перенос оффлайновых иерархий в сетевое общение (Daniels 2013), что снижает потенциал общественного давления.

Несмотря на актуальность этой проблемы, изучение стратегий обвинения в текстах социальных медиа практически не проводится. В когнитивистике, впрочем, нет согласия по поводу того, насколько обвинение в принципе является нормой в ситуации конфликта (Писарева, Гриценко 2011). Так, в 1990-е гг. считалось, что обвинение и самообвинение связаны с психическим состоянием респондентов (Tennen, Affleck 1990), но позже было показано, что перекладывание вины на «систему» помогает физиологической адаптации (LaVeist et al. 2001), т.е. является ожидаемым ответом на конфликт. При этом в научно-правовом дискурсе доминирует иное содержание термина «вина»-как доказанной персональной причинности при нарушении закона (Дмитриева 2011).

Англоязычная литература во многом сфокусирована на феномене обвинения жертв конфликта (victim blaming), который особенно заметен в дискуссиях, ценностно поляризующих общество (Stubbs-Richardson et al. 2018). Обвинения в соцсетях колеблются между тремя разными по природе полюсами: обсуждением вины акторов конфликтов как политического явления, упоминанием персональной вины преступников и обвинением жертв. Поэтому мы будем использовать анализ заявлений, claim-making analysis (Koopmans, Statham 1999), как метод оценки текста, позволяющий включить в рассмотрение все три вида обвинений.

\section{Иммигранты в России и Германии и их обсуждение в традиционных и социальных медиа}

В фокус нашего внимания попали конфликты с насильственным триггером, в которых межличностный конфликт «вскрывает» межгрупповой 
конфликт, имеющий этнорелигиозную и мигрантскую составляющие. В силу этнитизации и исламизации темы миграции в публичной дискуссии (Малахов 2004; Bodrunova et al. 2017a) в таких конфликтах межэтническая напряженность раскрывается в многообразии ее контекстов.

Российские конфликты, выбранные нами, включают убийство Егора Щербакова Орханом Зейналовым и последующие народные волнения в Бирюлево (Москва) в 2013 г. и убийство ребенка няней-узбечкой Гюльчехрой Бобокуловой в 2016 г. Конфликты в Германии включают массовое насилие над женщинами в новогоднюю ночь 2015-2016 г. в Кельне и наезд автобуса на рождественскую ярмарку в Берлине в 2016 г. Во всех этих случаях триггер был создан представителями иммигрантских сообществ, понимаемых как отличных по фенотипу, языку и религиозным предпочтениям. За этим последовала реакция принимающего сообщества, в т. ч. с выходом на улицы и/или обсуждением в соцсетях (тематика попадала в мировые и/или национальные тренды Твиттера). Дискуссии в соцсетях включали вопросы о миграционной политике (закрытие рынков, введение виз для иммигрантов, политика приема беженцев, политика безопасности для городской среды) и вовлекала представителей власти.

\section{Иммигранты в медиа России и Германии: недопредставленность и демонизация}

На иммигрантские сообщества в силу их стигматизации потенциально направлено повышенное внимание обвинителей. А неполная включенность иммигрантов в публичную сферу (Зверева 2014) не оставляет шансов на равный ответ (Bleich et al. 2015). В постсоветской России публичный дискурс о мигрантах складывался из властного дискурса (которому часто противостоял дискурс чиновный), масс-медийного и редко актуализируемого академического. К началу 2010-х гг. они переплелись, и на фоне роста неприятия иммигрантов (Bessudnov 2016) доминантами стали: указание на этничность иммигрантов; миф о большом вкладе «приезжих» из Центральной Азии в рост преступности (Мукомель 2011); дуализм в речах федеральных и региональных чиновников - нужда в рабочих руках vs. необходимость введения виз (Bodrunova et al. 2017a); замалчивание конфликтов и общая неуверенность в том, как освещать в СМИ межэтнические кризисы (Hutchins, Tolz 2015).

Еще одной чертой миграционного дискурса стало нарастание межэтнической проблематики в блогах и социальных медиа (Bodrunova et al. 2017b), где формируется собственная повестка обсуждения (Мукомель 2011; Apishev et al. 2016). При этом в публичном поле сложились две коалиции в сфере политики о миграции: во-первых, заинтересованные в субсидиях коммерческие структуры и активисты-«квазиправозащитники», а, во-вторых, немногочисленные активисты, работающие с реальными проблемами иммигрантов (Кондаков 2015). Исследователи подчеркивают жесткость 
дискурса о мигрантах, в котором очевидны обвинительная модальность высказываемой позиции (Викулова, Серебренникова 2014), стабильность негативных аттитюдов даже в ситуации контакта с иммигрантами (Соколов 2017), рост поляризации по оси «свой - чужой» (Мукомель 2014), роль политических акторов и СМИ в поддержании настороженного отношения к иммигрантам (Кугай, Ковалева 2015; Hutchins, Tolz 2015).

В Германии к 2015-2016 гг. повестка дня в публичных дебатах о миграции изменилась в связи с «миграционным кризисом». В 2000-е гг. внимание общества привлекали выходцы из Турции и стран бывшего $\mathrm{CCCP}$, а также репрезентации ислама в публичном дискурсе в целом (Bonfadelli, Moser 2007); «арабская весна» и сирийский кризис сместили повестку в сторону обсуждения ближневосточных групп переселенцев (Holmes, Castañeda 2016). Еще недавно дискурс об иммигрантах формировался как дискурс толерантности и о толерантности (Диденко 2017), но «кризис беженцев» выявил поляризацию населения и складывание анти-мигрантской «темной Германии» (Bodrunova et al. 2017b; Schelter, Kunegis 2017). При этом СМИ хранили подчеркнутый нейтралитет: многие редакционные гайдлайны прямо запрещали называть национальность правонарушителей в криминальных сводках.

\section{Контекст обсуждения конфликтов с участием иммигрантов}

Материалы нашего исследования анализируют онлайн-тексты о конфликтах и/или миграции с применением автоматизированных методов (Биккулов, Бершадская 2013; Apishev et al. 2016; Koltsova et al. 2017; Габриелова 2017; Bodrunova et al. 2016, 2017b). Показано, что следует принять во внимание дискурсивные и медийные факторы. И в Германии, и в России обсуждение вопросов миграции связано с дискуссией о национализме (Elwert 1989; Дробижева 2013), так как связь иммиграции с исламом является предметом религиозно-обусловленной нетолерантности, угроз, призывов к насилию от сторонников «чистоты нации» (Awan 2014; Bodrunova et al. 2017b). Также в обеих странах наблюдается напряженность между федеральным и региональным уровнем формирования миграционной политики.

Но в Германии иммигрантские сообщества на несколько лет раньше начали пользоваться гаджетами и выходить в социальные медиа (Hepp et al. 2011; Hinkelbein 2014; Кужелева-Саган 2016). В Германии интенсивность пользования Твиттером политиками, госорганами и НКО выше, чем в России, и мы ожидаем большее присутствие иммигрантского сообщества и институтов в немецком Твиттере. К тому же разная степень гражданственности общества в России и Германии позволяет ожидать, что в России промигрантские голоса не будут связаны с НКО, тогда как в Германии иммигрантов, говоря простым языком, будет кому защищать. 


\section{Гипотезы и методология исследования}

Исходя из вышеизложенного, мы сформулировали пять гипотез.

- H1. Объем твитов с указанием на возложение вины и/или ответственности за конфликт выше в российском Твиттере, чем в немецком.

- H2. Статус пользователя связан с избираемыми им паттернами вины и ответственности.

- Н3. В России основным объектом обвинения выступают иммигранты (индивидуально и как сообщество), а в Германии - государственные органы.

- Н4. В обеих странах обвинения будут звучать в адрес федеральных властей, а разрешения конфликта люди будут ждать от региональных властей.

- Н5. В обеих странах объем обвинения жертв будет пренебрежимо мал.

Общая методология проекта описана нами ранее (Bodrunova et al. 2016, 2017 b), здесь мы опишем лишь ход данного исследования. Оно включало следующие этапы: (1) отбор кейсов (с помощью сервиса trendinalia.com); (2) формирование наборов ключевых слов (словарей) для веб-краулинга; (3) веб-краулинг на основе словарей. На последней стадии загружались метаданные и твиты пользователей (шаг 1), а также метаданные пользователей, комментировавших, ретвитивших или лайкавших собранные твиты, для дальнейшего определения влиятельных пользователей в выборке шага 1 (шаг 2).

Пользователи шага 1 ранжировались по числу твитов, и для каждого набора данных вычислялся порог активности пользователей $K$, с тем чтобы сформировать выборки твитов сравнимого объема и репрезентативности для обработки в ручном режиме. После препроцессинга и очистки от нерелевантных твитов получены выборки по конфликтным событиям: Бирюлево - 1099, Бобокулова - 1513, Берлин - 1437, Кельн - 2525 твитов. В случае Кельна выборка построена путем обогащения сокращенной выборки твитов «обычных» людей твитами медиа из числа влиятельных пользователей, т.к. первичная выборка слишком велика для ручного анализа.

Выборки закодированы вручную (Cohen's Kappa for two coders). Каждый твит кодировался по пяти переменным: (1) статус пользователя: системный политический актор, внеститемный актор (НКО / представитель радикальной группы / представитель диаспоры), медиа, обычный пользователь; (2) наличие фрейма обвинения или (3) фрейма ответственности; (4) адресат обвинения или (5) возложения ответственности: федеральная власть и национальный лидер, региональная власть и полиция, иммигрантское сообщество, иммигрант(ы) - триггер(ы) конфликта, жертва или все общество, медиа, политические группы, иное. Спорные случаи обсуждались рабочей группой. 
Для оценки связи переменных применялась корреляция Спирмена. Выборки твитов подвергались экспертному чтению. Ограничения метода включали невозможность гарантировать принадлежность твитов к географическому региону и невозможность собрать твиты, размещенные «под замком»; но мы заинтересованы в изучении публичного дискурса, а подавляющее большинство твитов на немецком и русском принадлежит жителям Германии и России, поэтому данные ограничения несущественны.

В определении стилистики высказывания, указывающего на вину/ ответственность, мы пользовались наработками claim-making analysis и теории фрейминга (Fuersich 2009). Так, принималось в расчет только активное возложение вины и/или ответственности, отличное от критики акторов и призыва к действию. Брались в расчет фреймы вины и ответственности «за пределами» триггера, разъясняющие причины триггерного события, предъявляющие претензии к персонам или социальным группам, сравнивающие триггерное событие с иными подобными. Не кодировались попытки снятия вины и защиты триггеров конфликта и иных акторов.

\section{Результаты: паттерны вины и ответственности в Твиттере России и Германии}

Обвинение и высказывание ожиданий разрешения конфликтов присутствует, как и ожидалось, в Твиттере в обеих странах. Гипотеза 1 касалась объема таких высказываний; (рис. 1): как видно Гипотеза 1 должна быть отвергнута, т.к. объем таких твитов в Германии почти в полтора раза выше, чем в России. Интересно сопоставить кейсы с групповым (Бирюлево и Кельн) и индивидуальным триггером (Бобокулова и Берлин). Групповые конфликты демонстрируют сопоставимый паттерн, а в берлинском кейсе обсуждение ответственных занимает намного больше места относительно и российских, и кельнского кейса. Подробное чтение твитов показывает, что разница обусловлена доминированием нейтрального новостного дискурса в кейсе Бобокуловой и тем, что пользователи в России часто констатируют бессилие властей.

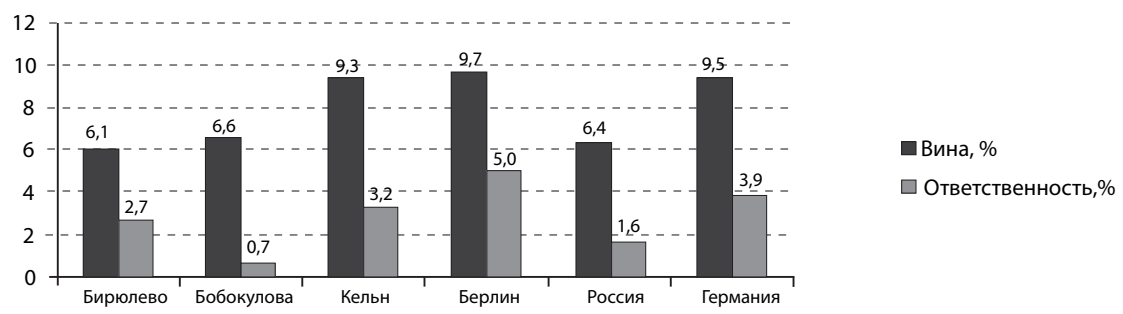

Puc. 1. Объем твитов с фреймами возложения вины и ответственности, в\% от числа твитов по кейсу/стране 
Гипотеза 2 касалась связи статуса пользователя и адресата обвинения. Как видно (табл. 1), в двух из четырех кейсов статус пользователя слабо коррелирует с его/ее мнением о том, кто несет вину за конфликт. Иначе говоря, в половине случаев НКО, государственные акторы и обычные пользователи действительно направляют гнев и обвинения на разных субъектов. Малый объем найденных твитов не позволяет подтвердить Гипотезу 2, но искомая связь очевидна в половине кейсов минимум, при том что в анализ вошли только случаи прямого обвинения и возложения ответственности. Обвинительный дискурс «разлит» в Твиттере в обеих странах, но все же по-разному. Так, в кейсе Бобокуловой, твиты пропитаны дискурсом о вине почти без ее возложения на конкретных акторов. В марте большинство пользователей, включая медиа, называли Бобокулову «няняубийца» еще до решения суда; в октябре ситуация повторилась, хотя суд отказался назначить Бобокуловой уголовное наказание. При этом в берлинском кейсе водители автобуса назывались подозреваемыми, а не убийцами, даже когда вина тунисца Амира Амри казалась очевидной, что позволило немецким СМИ сохранить лицо при смене подозреваемого.

Табл. 1

Связь статуса пользователя и адресата возложения вины и ответственности, корреляция Спирмена

\begin{tabular}{l|l|l}
\hline \multicolumn{1}{c|}{ Кейс/страна } & Паттерн вины & Паттерн ответственности \\
\hline Бирюлево & 0,010 & - \\
Бобокулова & $0,237^{* *}$ & - \\
Кельн & $0,136^{*}$ & 0,182 \\
Берлин & 0,067 & 0,111 \\
Россия в целом & 0,141 (sig. 0,069) & 0,048 \\
Германия в целом & 0,095 (sig. 0,065) & $0,171^{*}$ \\
\hline
\end{tabular}

Примечание. Прочерк означает недостаточное количество данных для анализа.

Гипотезы 3, 4 и 5 касались адресатов обвинения и возложения ответственности в разных странах. Результаты анализа адресатов обвинения и возложения вины представлены для России (рис. 2) и для Германии (рис. 3). При этом Гипотеза 3 о том, что в России основным объектом обвинения выступают мигранты, а в Германии - госорганы, должна быть отвергнута.

В конфликтах с групповым триггером наблюдаются сходные паттерны присвоения вины: в обеих странах лидируют региональные власти и полиция, затем идет федеральная власть, затем мигранты в целом. Обвинения ложатся либо на лидера страны (особенно на Ангелу Меркель, персонифицирующую политику толерантности), либо на правительство в целом 
(«Правительство готово трусливо спрятаться за овощей-оккупантов, подло предав свой народ - лишь бы сохранить власть»). Но наблюдается разница в объеме агрессии по отношению к иммигрантам: в российском Твиттере присутствуют и сарказм, и ноты ненависти, а в немецком - сарказм соседствует с признанием своей вины политиками и призывами выяснить, кто все-таки виноват. Также имеется разница в присвоении вины иным акторам. Если в России почти нет обвинений ни СМИ, ни политических групп, то в Германии их объем сравним с объемом обвинений в сторону триггера. В случае Кельна это связано с молчанием СМИ по поводу конфликта и ожиданиями граждан, что СМИ будут более жестко и правдиво освещать роль иммигрантов в нападениях на женщин. Также политическая поляризация и ее отражение в паттернах обвинения очевидно отличает немецкий Твиттер от российского: так, участок дискуссии под феминистским хэштегом \#ausnahmslos («без исключения») снимает вину с мигрантов и перекладывает ее на сексистское общество, в то время как радикальный хэштег \#еinearmlaenge, появившийся после рекомендации одного из политиков женщинам держаться «на расстоянии вытянутой руки» от мужчин, использовался для критики не только правительства и политики толерантности, но также феминистских групп. По ходу дискуссии оба хэштега обросли саркастическим дискурсом, противоположным по смыслу. Обвинялись также политические партии - как ХДС/ХСС, так и СПД.

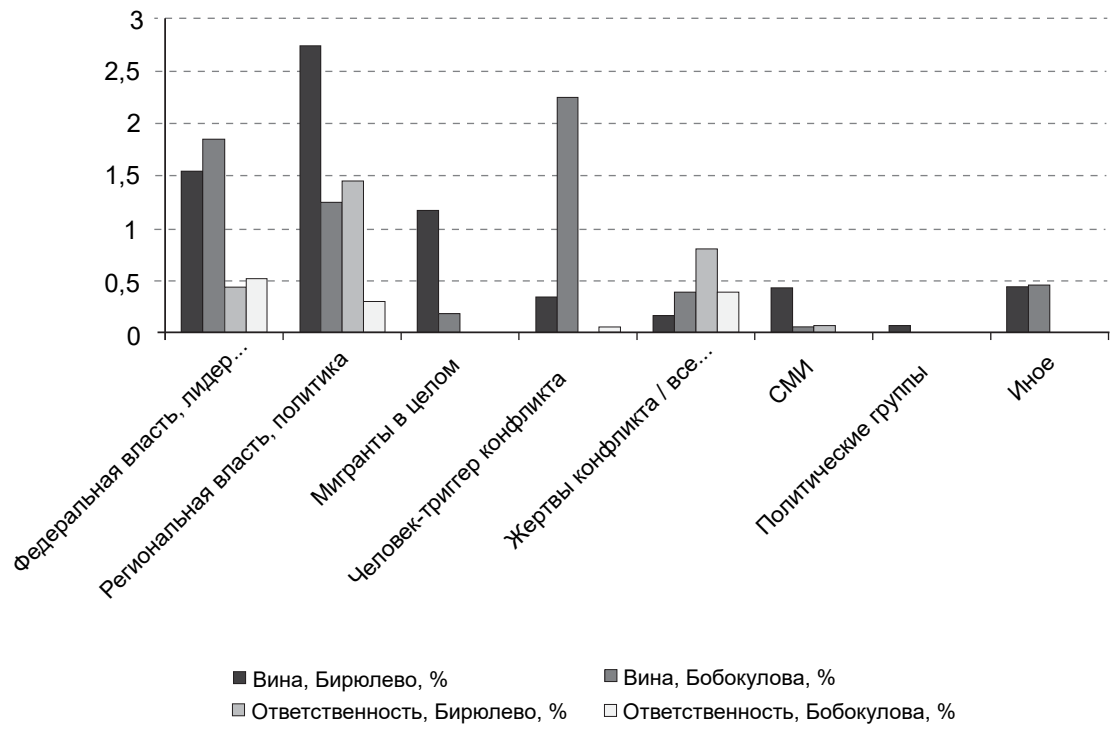

Рис. 2. Распределение паттернов вины и ответственности, российские кейсы 


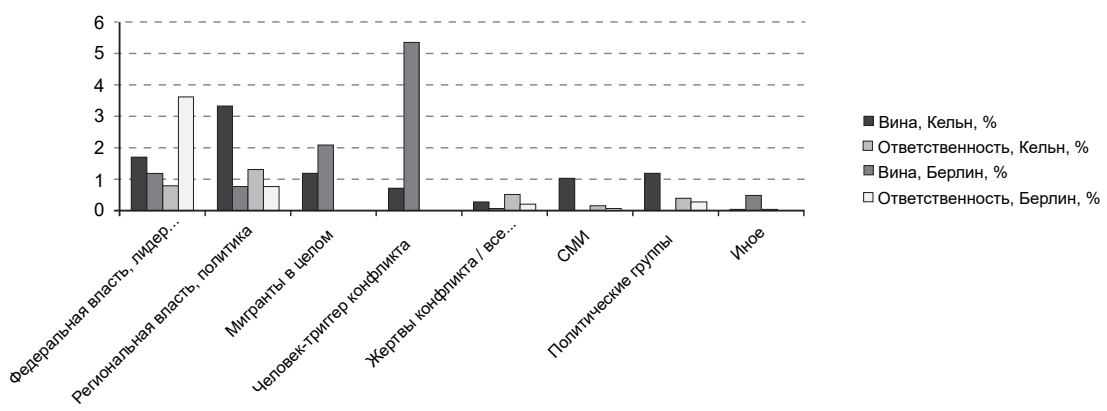

Рис. 3. Распределение паттернов вины и ответственности, немецкие кейсы

В случае Кельна мы могли сравнить медиадискурс с дискурсом «обычных пользователей» (рис. 4). Видно, что последний является гораздо более жестким с точки зрения наличия обвинений и отличается от первого по структуре. Наибольшую вину пользователи возлагают на политических игроков: федеральное правительство, региональные власти, политические партии, тогда как медиа больше обвиняют полицию (хотя есть и твиты о ее эффективной работе), а также пишут о том, что среди обвиняемых есть иммигранты. Именно пользователи налагают вину на медиа и политические группы, а СМИ обвиняют скорее местные власти и не налагают ни вину, ни ответственность на федеральное правительство.

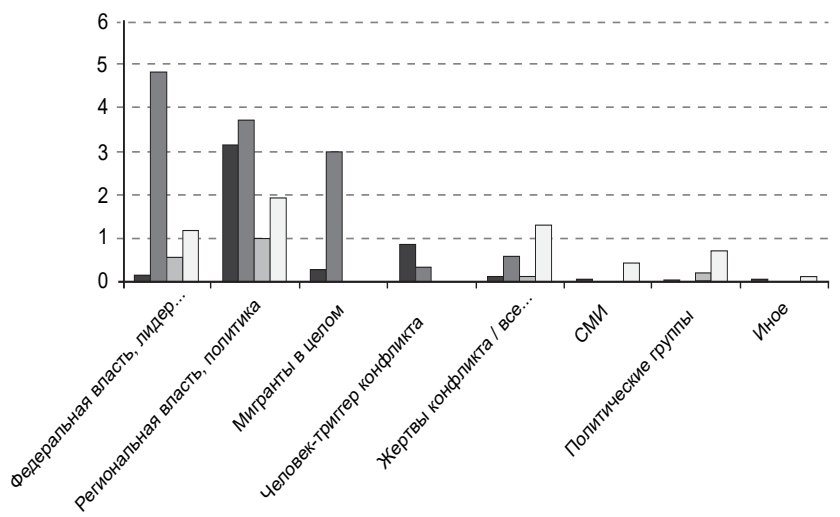

Вина, медиа, \%

口 Ответственность, медиа, \%

口Вина, обычные, \%

口Ответственность, обычные,

Рис. 4. Паттерны вины и ответственности в кейсе Кельна: сопоставление дискурса СМИ и «обычных пользователей» 
В кейсе Кельна медийные твиты абсолютно не отражают картину поляризованных настроений пользователей, ограничиваясь констатациями и репортажами о подробностях конфликта. Но и между газетами есть различия: так, только таблоид Bild четко указывает, что в насилии в Кельне виноваты иностранцы; СМИ левого спектра, такие как Sueddeutsche Zeitung и Der Freitag, осторожны в формулировках и нейтральны к иммигрантам.

В конфликтах с индивидуальным триггером паттерн вины иной: основной объем обвинений переложен на виновника/виновницу конфликта, и большую роль в этом в обеих странах играет медийный дискурс, освещающий детали расследования и ареста. Но следует обратить внимание на намного больший объем обвинений в сторону властей в России и в сторону иммигрантских групп - в Германии.

Следует признать Гипотезы 3 и 4 опровергнутыми. Реальность дискуссии оказалась противоположна ожиданиям в обеих странах: вина ложится на региональные власти и полицию, а разрешения конфликта люди ожидают от федеральных властей, связывая конфликты с ошибками в миграционной политике. Подтверждена Гипотеза 5: твиты, обвиняющие жертв, во всех конфликтах оказались единичными, а вина и ответственность ложатся на общество, а не на пострадавших. При этом ответственность общества формулируется по-разному. В обеих странах присутствуют радикальные призывы к объединению и «наведению порядка»: «Отвратительные лицемеры! Закончите уже эту \#Asylpolitik! [\#политикуубежища!»] или «Ору папе БЕЙ ХАЧЕЙ! папа в ответ орет из другой комнаты СПАСАЙ РОССИЮ». Однако в Германии также присутствует контрдискурс о необходимости толерантности и снижения уровня сексизма в обществе.

\section{Заключение}

Вопреки ожиданиям, паттерны наложения вины и ответственности в российском и немецком Твиттере в целом сходны, причем объем обвинений в немецком Твиттере больше. В групповых конфликтах виноватыми признаются федеральная и местная власти и в меньшей степени иммигранты, в конфликтах с персональным триггером - зачинщики конфликта. В том, на кого возлагаются вина и ответственность отражается состояние каждого из обществ. Так, в Германии, где медиа и партии активно влияют на миграционную политику, мы видим политическую поляризацию обвинений и выпады в сторону СМИ; но дискурс защиты беженцев и медийный нейтралитет отчасти компенсируют разлом между радикальными феминистками и сторонниками неоконсервативного движения. В российском Твиттере обвинители более солидарны и более агрессивны, а призывы к объединению против неугодных иммигрантских групп ничем не компенсируются, в то время как ожидания, что ситуация разрешится политически ниже в сравнении с Германией. 


\section{Выражение признательности}

Исследование выполнено при поддержке Российского научного фонда (проект № 16-18-10125).

\section{Список источников}

Биккулов А.С., Бершадская Л.А. (2013) Обсуждение проблемы мигрантов, а также разжигание межнациональной розни в социальных сетях, блогах и форумах. Современные проблемы науки и образования, (5): 653-653.

Викулова Л.Г., Серебренникова Е. Ф. (2014) Структуры и способы конструирования социальной реальности в медийном дискурсе (предметная область иммиграция). Вестник Нижневартовского государственного университета, (4): 10-16.

Габриелова Е. В. (2017) Имлицитное и эксплицитное выражение оценки проблемы миграции в современном мире в микроблоге Твиттер. Bulletin of Moscow State Regional University, (4): 1-9.

Диденко В.И. (2017) Толерантность к мигрантам в русском, американском и немецком медиадискурсе: основные дискурсивные стратегии. Вестник Челябинского государственного университета, серия «Филологические науки», (108): 35-44.

Дмитриева О.В. (2011) Римские правовые конструкции вины и ответственности и их влияние на современное гражданское право России. Юридические записки, (1): $124-130$.

Дробижева Л.М. (2013) Этничность в социально-политическом пространстве Российской Федерациии: Oпыт 20 лет. М: Новый хронограф.

Зверева Н.Ю. (2014) Дискурсы о мигрантах в современной российской прессе: стратегии борьбы за значение. Новое литературное обозрение, (4): 88-95.

Калыгина М.Ю. (2009) Метафорическая репрезентация миграции в медиадискурсе России, Великобритании и США. Политическая лингвистика, (29): 109-113.

Кондаков А. (2015) Возможности взаимодействия между акторами в миграционной политике России. Журнал социологии и социальной антропологии, 4 (81): 174-186.

Кугай А.И., Ковалева А.М. (2015) Расистский дискурс электронных СМИ как фактор конструирования межэтнических конфликтов. Управленческое консультирование, 1 (73): 86-93.

Кужелева-Саган И. П. (ред.) (2016) «Цифровые диаспоры» мигрантов из Центральной Азии: виртуальная сетевая организачия, дискурс «воображаемого сообщества» и конкуренция идентичностей. Томск: Изд-во Томского ун-та.

Малахов В. (2004) Этнизация феномена миграции в публичном дискурсе и институтах: случай России и Германии. Т. Бараулина, О. Карпенко (ред.) Миграџия и нащиональное государство. СПб: ЦНСИ: 85-86.

Мукомель В.И. (2011) Российские дискурсы о миграции: «нулевые годы». Россия реформирующаяся, (10): 86-109.

Мукомель В.И. (2014) Ксенофобия и мигрантофобии в контексте культуры доверия. Мир России. Социология. Этнология, 23 (1): 137-166.

Нестерова Я.А., Бурова Е.А. (2016) К вопросу об особенностях употребления метафор в миграционном дискурсе Германии, Австрии, Англии и Америки. Российский гуманитарный журнал, 5 (6): 565-571. 
Писарева О. Л., Гриценко А. (2011) Когнитивная регуляция эмоций. Философия и социальные науки: Научный журнал, (2): 64-69.

Свинкина М.Ю. (2016) Стратегия субъективизации чужого и тактики речевого воздействия (на примере новостных источников российских и немецких СМИ). А.В. Виноградов (отв. ред.) Современные проблемы языкознания, литературоведения, межкультурной коммуникации и лингводидактики. Белгород: ИД Белгород:409-413.

Соколов Н.В. (2017) Работящие, но чужие: парадокс восприятия мигрантов массовым сознанием (по результатам исследований в Санкт-Петербурге). Мониторинг общественного мнения: экономические и социальные перемены, 1 (137): 80-96.

Apishev M., Koltcov S., Koltsova O., Nikolenko S., Vorontsov K. (2016) Mining Ethnic Content Online with Additively Regularized Topic Models. Computacion y Sistemas, 20 (3): 387-403.

Awan I. (2014) Islamophobia and Twitter: A Typology of Online Hate Against Muslims on Social media. Policy \& Internet, 6 (2): 133-150.

Bessudnov A. (2016) Ethnic Hierarchy and Public Attitudes Towards Immigrants in Russia. European Sociological Review, 32 (5): 567-580.

Bleich E., Bloemraad I., de Graauw E. (2015) Migrants, Minorities and the Media: Information, Representations and Participation in the Public Sphere. Journal of Ethnic and Migration Studies, 41 (6): 857-873.

Bodrunova S. S., Blekanov I. S., Smoliarova A. S., Litvinenko A. A. (2019) Beyond Left and Right: Multi-cluster Political Polarization in Twitter Discussions on Inter-ethnic Conflicts in Russia, Germany, and the USA. Media and Communication, 2, forthcoming.

Bodrunova S. S., Koltsova O., Koltcov S., Nikolenko S. (2017a) Who's bad? Attitudes toward Resettlers from the Post-Soviet South versus Other Nations in the Russian Blogosphere. International Journal of Communication, (11):3242-3264.

Bodrunova S. S., Litvinenko A. A., Blekanov I. S. (2017b) Comparing Influencers: Activity vs. Connectivity Measures in Defining Key Actors in Twitter ad Hoc Discussions on Migrants in Germany and Russia. Lecture Notes in Computer Science, 10539:360-376.

Bodrunova S. S., Litvinenko A. A., Blekanov I. S. (2016). Influencers on the Russian Twitter: Institutions vs. People in the Discussion on Migrants. $3^{\text {rd }}$ International Conference on Electronic Governance and Open Society: Challenges in Eurasia, St. Petersburg, November 22-23. ACM:212-222.

Bonfadelli H., Moser H. (eds.) (2007) Medien und Migration: Europa als multikultureller Raum? Wiesbaden: Springer.

Daniels J. (2013) Race and Racism in Internet Studies: A Review and Critique. New Media \& Society, 15 (5): 695-719.

Elwert G. (1989) Nationalismus und Ethnizität: Über die Bildung von Wir-Gruppen. Kölner Zeitschrift für Soziologie und Sozialpsychologie, 41 (3): 440-464.

Fuersich E. (2009) In Defense of Textual Analysis. Restoring a Challenged Method for Journalism and Media Studies. Journalism Studies, (10): 238-252.

Hepp A., Bozdag C., Suna L. (2011) Mediale Migranten. Cham: Springer.

Heverin T., Zach L. (2012) Use of Microblogging for Collective Sense-making during Violent Crises: A Study of Three Campus Shootings. Journal of American Society of Information, Science and Technology, (63):34-47.

Hinkelbein O. (2014) Digitale Integration von Migranten?: Ethnographische Fallstudien zur digitalen Spaltung in Deutschland. Berlin: Transcript Verlag. 
Holmes S. M., Castañeda H. (2016) Representing the 'European Refugee Crisis' in Germany and Beyond: Deservingness and Difference, Life and Death. American Ethnologist, 43 (1): 12-24.

Hutchinson S., Tolz V. (2015) Nation, Ethnicity and Race on Russian Television: Mediating Post-Soviet Difference. New York: Routledge.

Koltsova O., Nikolenko S., Alexeeva S., Nagornyy O., Koltcov S. (2017) Detecting Interethnic Relations with the Data from Social Media. International Conference on Digital Transformation and Global Society, St.Petersburg, June 22-24. Cham: Springer: 16-30.

Koopmans R., Statham P. (1999) Challenging the Liberal Nation-state? Postnationalism, Multiculturalism, and the Collective Claims Making of Migrants and Ethnic Minorities in Britain and Germany. American Journal of Sociology, 105 (3): 652-696.

Lasorsa D. L., Lewis S. C., Holton A.E. (2012) Normalizing Twitter: Journalism Practice in an Emerging Communication Space. Journalism Studies, 13 (1): 19-36.

LaVeist T. A., Sellers R., Neighbors H. W. (2001) Perceived Racism and Self and System Blame Attribution: Consequences for Longevity. Ethnicity \& Disease, 11 (4): 711-721.

Patrona M. (ed.) (2018) Crisis and the Media: Narratives of Crisis across Cultural Settings and Media Genres. Amsterdam: John Benjamins.

Pöttker H. (2006) Integration durch Massenmedien: Medien und Migration im internationalen Vergleich. Berlin: Transcript Verlag.

Schelter S., Kunegis J. (2017) 'Dark Germany': Temporal Characteristics and Connectivity Patterns in Online Far-Right Protests Against Refugee Housing. Proceedings of the 2017 ACM on Web Science Conference, June 25-28, Troy, New York, USA. ACM:415-416.

Stubbs-Richardson M., Rader N.E., Cosby A. G. (2018) Tweeting Rape Culture: Examining Portrayals of Victim Blaming in Discussions of Sexual Assault Cases on Twitter. Feminism \& Psychology, 28 (1): 90-108.

Tennen H., Affleck G. (1990) Blaming Others for Threatening Events. Psychological Bulletin, 108 (2): 209-232.

Trottier D., Fuchs C. (eds.) (2014). Social Media, Politics and the State: Protests, Revolutions, Riots, Crime and Policing in the Age of Facebook, Twitter and Youtube. London: Routledge.

Tufekci Z. (2014) Social Movements and Governments in the Digital Age: Evaluating a Complex Landscape. Journal of International Affairs, 68 (1): 1-18.

United Nations (2013) Trends in International Migrant Stock: The 2013 Revision. Available at: www.un.org/en/development/desa/population/migration/data/estimates2/estimatestotal.shtml (accessed 15 September 2018). 
Svetlana Bodrunova, Anna Smoliarova

Vera Achkasova, Ivan Blekanov

\section{WHO IS TO BLAME? PATTERNS OF BLAMING AND RESPONSIBILITY ASSIGNMENT IN NETWORKED DISCUSSIONS ON IMMIGRANTS IN RUSSIA AND GERMANY}

The conflicts between host communities and re-settlers from global or postSoviet 'South' and public discussions on such conflicts have become a vivid feature of today's public spheres in both Europe and Russia. Discussions in social media may put pressure upon immigration policing, as they reflect both consensual and conflictual public moods. Thus, it is crucial to know who (including actors and institutions) social media users see as the culprits in this conflict and who is expected to resolve these problems. We look at four Twitter discussions on the conflicts involving re-settlers in Russia and Germany of 2013-16 and assess whether the user type correlates with blaming and responsibility patterns. We also describe the discursive strategies of blaming in the two countries. The methods of data collection and analysis include vocabulary-based web crawling, expert evaluation of user types, manual coding of tweets, and descriptive statistics. Our results suggest that, contrary to expectations, the blaming patterns are similar: the main blame is put on regional authorities and police, federal government and national leaders, and immigrant groups. While blaming them, people expect the resolution of the conflicts from the federal government, who is seen to be responsible for immigration policies. Also, while in Germany we detect fierce mutual blaming by pro-nationalist and feminist groups partly compensated by neutral media discourse, in the world of Russian Twitter, we see a onesided blaming of authorities and immigrants in the absence of institutional mediation of the discussion, as well as low expectations of non-violent political resolutions of inter-ethnic tensions.

Keywords: immigrants, inter-ethnic conflict, Twitter, Germany, Russia

DOI: 10.17323/727-0634-2018-16-4-627-644

Svetlana S. Bodrunova - Dr. hab. in Political Science, Professor, School of Journalism and Mass Communications, St. Petersburg State University, St. Petersburg, Russian Federation. Email: s.bodrunova@spbu.ru

Anna S. Smoliarova - PhD in Political Science, Associate Professor, School of Journalism and Mass Communications, St. Petersburg State University, St. Petersburg, Russian Federation. Email: a.smoliarova@spbu

Vera A. Achkasova - Dr. hab. in Political Science, Professor, School of Journalism and Mass Communications, St. Petersburg State University, St. Petersburg, Russian Federation. Email: v.achkasova@spbu.ru

Ivan S. Blekanov - PhD in Technical Sciences, Associate Professor, Faculty of Applied Mathematics and Control Processes, St. Petersburg State University, St. Petersburg, Russian Federation. Email: i.blekanov@spbu.ru 


\section{References}

Apishev M., Koltcov S., Koltsova O., Nikolenko S., Vorontsov K. (2016) Mining Ethnic Content Online with Additively Regularized Topic Models. Computacion y Sistemas, 20(3):387-403.

Awan I. (2014) Islamophobia and Twitter: A Typology of Online Hate against Muslims on Social Media. Policy \& Internet, 6 (2): 133-150.

Bessudnov A. (2016) Ethnic Hierarchy and Public Attitudes towards Immigrants in Russia. European Sociological Review, 32 (5): 567-580.

Bikkulov A.S., Bershadskaya L.A. (2013) Obsuzhdeniye problemy migrantov, a takzhe razzhiganiye mezhnatsional'noy rozni v sotsial'nykh setyakh, blogakh i forumakh [Discussing the Issue of Migrants and Inciting Ethnic Hatred in Social Networks, Blogs, and Forums]. Sovremennyye problemy nauki i obrazovaniya [Modern Problems of Science and Education], (5): 653-653.

Bleich E., Bloemraad I., de Graauw E. (2015) Migrants, Minorities and the Media: Information, Representations and Participation in the Public Sphere. Journal of Ethnic and Migration Studies, 41 (6): 857-873.

Bodrunova S. S., Blekanov I. S., Smoliarova A. S., Litvinenko A. A. (2019 Forthcoming) Beyond Left and Right: Multi-cluster Political Polarization in Twitter Discussions on Inter-ethnic Conflicts in Russia, Germany, and the USA. Media and Communication.

Bodrunova S. S., Koltsova O., Koltcov S., Nikolenko S. (2017a) Who's Bad? Attitudes toward Resettlers from the Post-soviet South versus Other Nations in the Russian blogosphere. International Journal of Communication, (11): 3242-3264.

Bodrunova S. S., Litvinenko A. A., Blekanov I. S. (2017b) Comparing Influencers: Activity vs. Connectivity Measures in Defining Key Actors in Twitter Ad Hoc Discussions on Migrants in Germany and Russia. Lecture Notes in Computer Science, 10539:360-376.

Bodrunova S. S., Litvinenko A. A., Blekanov I. S. (2016). Influencers on the Russian Twitter: Institutions vs. People in the Discussion on Migrants. $3^{\text {rd }}$ International Conference on Electronic Governance and Open Society: Challenges in Eurasia, St. Petersburg, November 22 23. ACM:212-222.

Bonfadelli H., Moser H. (eds.) (2007) Medien und Migration: Europa als multikultureller Raum? Wiesbaden: Springer.

Daniels J. (2013) Race and Racism in Internet Studies: A Review and Critique. New Media \& Society, 15 (5): 695-719.

Didenko V.I. (2017) Tolerantnost' k migrantam v russkom, amerikanskom i nemetskom mediadiskurse: osnovnyye diskursivnyye strategii [Tolerance towards Migrants in the Russian, American, and German Media Discourse: The Basic Discursive Strategies]. Vestnik Chelyabinskogo gosudarstvennogo universiteta, seriya 'Filologicheskiye nauki' [Bulletin of Chelyabinsk State University, 'Philological sciences' series], (108):35-44.

Dmitriyeva O. V. (2011) Rimskiye pravovyye konstruktsii viny i otvetstvennosti i ikh vliyaniye na sovremennoye grazhdanskoye pravo Rossii [Constructs of Guilt and Responsibility in Roman Law and Their Impact Upon Today's Civic Law in Russia]. Yuridicheskiye zapiski [Juridical Bulletin], (1): 124-130.

Drobizheva L.M. (2013) Etnichnost'v sotsial'no-politicheskom prostranstve Rossiyskoy Federatsii: Opyt 20 let [Ethnicity in Social and Political Space of the Russian Federation: The Experience of 20 years]. Moscow: Novyy khronograf.

Elwert G. (1989) Nationalismus und Ethnizität: Über die Bildung von Wir-Gruppen. Kölner Zeitschrift für Soziologie und Sozialpsychologie, 41 (3): 440-464. 
Fuersich E. (2009) In Defense of Textual Analysis. Restoring a Challenged Method for Journalism and Media Studies. Journalism Studies, (10):238-252.

Gabriyelova E. V. (2017) Implitsitnoye i eksplitsitnoye vyrazheniye otsenki problemy migratsii v sovremennom mire v mikrobloge Tvitter [Implicit and Explicit Expression of Evaluation of the Problem of Migration in Today's World in Twitter]. Vestnik Moscovskogo gosudarstvennogo oblastnogo universiteta [Bulletin of Moscow State Regional University], (4): 1-9.

Hepp A., Bozdag C., Suna L. (2011) Mediale Migranten. Cham: Springer.

Heverin T., Zach L. (2012) Use of Microblogging for Collective Sense-making during Violent Crises: A Study of Three Campus Shootings. Journal of American Society of Information, Science and Technology, (63):34-47.

Hinkelbein O. (2014) Digitale Integration von Migranten?: Ethnographische Fallstudien zur digitalen Spaltung in Deutschland. Berlin: Transcript Verlag.

Holmes S. M., Castañeda H. (2016) Representing the 'European Refugee Crisis' in Germany and beyond: Deservingness and Difference, Life and Death. American Ethnologist, 43 (1): 12-24.

Hutchinson S., Tolz, V. (2015) Nation, Ethnicity and Race on Russian Television: Mediating Post-Soviet Difference. New York: Routledge.

Kalygina M. Yu. (2009) Metaforicheskaya reprezentatsiya migratsii v mediadiskurse Rossii, Velikobritanii i Ssha [Metaphoric Representation of Migration in Media Discourse in Russia, Great Britain, and the USA]. Politicheskaya lingvistika [Political Linguistics], (29): 109-113.

Koltsova O., Nikolenko S., Alexeeva S., Nagornyy O., Koltcov S. (2017) Detecting Interethnic Relations with the Data from Social Media. International Conference on Digital Transformation and Global Society, St.Petersburg, June 22-24. Cham: Springer: 16-30.

Kondakov A. (2015) Vozmozhnosti vzaimodeystviya mezhdu aktorami v migratsionnoy politike Rossii [Possibilities of Interaction between Actors in the Russian Migration Policy]. Zhurnal sotsiologii i sotsial'noy antropologii [Journal of Sociology and Social Anthropology], 4 (81): 174-186.

Koopmans R., Statham P. (1999) Challenging the Liberal Nation-state? Postnationalism, Multiculturalism, and the Collective Claims Making of Migrants and Ethnic Minorities in Britain and Germany. American Journal of Sociology, 105 (3): 652-696.

Kugay A.I., Kovaleva A. M. (2015) Rasistskiy diskurs elektronnykh SMI kak faktor konstruirovaniya mezh etnicheskikh konfliktov [Racist Discourse of Electronic Media as a factor of Unfolding of Inter-ethnic Conflicts]. Upravlencheskoye konsul'tirovaniye [Managerial Consulting], 1 (73): 86-93.

Kuzheleva-Sagan I. P. (2016) 'Tsifrovyye diaspory' migrantov iz Tsentral'noy Azii: virtual'naya setevaya organizatsiya, diskurs 'voobrazhayemogo soobshchestva' i konkurentsiya identichnostey ['Digital Diasporas' of the Migrants from Central Asia: Virtual Network Organization, the Discourse of the 'Imagined Community' and Competition of Identities]. Tomsk: Izdvo Tomskogo un-ta.

Lasorsa D. L., Lewis S. C., Holton A. E. (2012) Normalizing Twitter: Journalism Practice in an Emerging Communication Space. Journalism Studies, 13 (1): 19-36.

LaVeist T. A., Sellers R., Neighbors H. W. (2001) Perceived Racism and Self and System Blame Attribution: Consequences for Longevity. Ethnicity \& Disease, 11 (4): 711-721.

Malakhov V. (2004). Etnizatsiya fenomena migratsii v publichnom diskurse i institutakh: sluchay Rossii i Germanii [Etnization of the Phenomenon of Migration in Public Discourse and Institutions: The Cases of Russia and Germany]. T. Baraulina, O. Karpenko (eds.) Migratsiya i natsional'noye gosudarstvo [Migration and Nation State]. St. Petersburg: TSNSI: 85-86. 
Mukomel' V. I. (2011) Rossiyskiye diskursy o migratsii: 'nulevyye gody' [Russian Discourses on Migration: The 2000s]. Rossiya reformiruyushchayasya [Russia Reforming Itself], (10): 86-109.

Mukomel' V. I. (2014) Ksenofobiya i migrantofobii v kontekste kul'tury doveriya [Xenophobia and Migrantophobias within the Context of the Culture of Trust]. Mir Rossii. Sotsiologiya. Etnologiya [The World of Russia. Sociology. Ethnology], 23 (1): 137-166.

Nesterova Y.A., Burova E. A. (2016) K voprosu ob osobennostyakh upotrebleniya metafor v migratsionnom diskurse Germanii, Avstrii, Anglii i Ameriki [On Use of Metaphors in the Discourse on Migration in Germany, Austria, the UK, and the USA]. Rossiyskiy gumanitarnyy zhurnal [Russian Journal of Humanities], 5 (6): 565-571.

Patrona M. (ed.) (2018) Crisis and the Media: Narratives of Crisis across Cultural Settings and Media Genres. Amsterdam: John Benjamins.

Pisareva O.L., Gritsenko A. (2011) Kognitivnaya regulyatsiya emotsiy [Cognitive Regulation of Emotions]. Filosofiya i sotsial'nyye nauki: Nauchnyy zhurnal [Philosophy and Social Sciences: A Scientific Journal], (2): 64-69.

Pöttker H. (2006) Integration durch Massenmedien: Medien und Migration im internationalen Vergleich. Berlin: Transcript Verlag.

Schelter S., Kunegis J. (2017) 'Dark Germany': Temporal Characteristics and Connectivity Patterns in Online Far-Right Protests Against Refugee Housing. Proceedings of the 2017 ACM on Web Science Conference, June 25-28, Troy, New York, USA. ACM:415-416.

Stubbs-Richardson M., Rader N.E., Cosby A. G. (2018) Tweeting Rape Culture: Examining Portrayals of Victim Blaming in Discussions of Sexual Assault Cases on Twitter. Feminism \& Psychology, 28 (1): 90-108.

Tennen H., Affleck G. (1990) Blaming Others for Threatening Events. Psychological Bulletin, 108 (2): 209-232.

Trottier D., Fuchs C. (eds.) (2014). Social Media, Politics and the State: Protests, Revolutions, Riots, Crime and Policing in the Age of Facebook, Twitter and Youtube. London: Routledge.

Tufekci Z. (2014) Social Movements and Governments in the Digital Age: Evaluating a Complex Landscape. Journal of International Affairs, 68 (1): 1-18.

United Nations (2013) Trends in International Migrant Stock: The 2013 Revision. Available at: http://www.un.org/en/development/desa/population/migration/data/estimates2/estimatestotal.shtml (accessed 15 September 2018).

Vikulova L. G., Serebrennikova E.F. (2014) Struktury i sposoby konstruirovaniya sotsial'noy real'nosti v mediynom diskurse (predmetnaya oblast' immigratsiya) [Structures and Means of Construction of Social Reality in Media Discourse]. Vestnik Nizhnevartovskogo gosudarstvennogo universiteta [Bulletin of Nizhnevartovsk State University], (4): 10-16.

Zvereva N. Y. (2014) Diskursy o migrantakh v sovremennoy rossiyskoy presse: strategii bor'by za znacheniye [Discourses on Migration in Today's Russian Press: Strategies of Struggling for Meanings]. Novoye literaturnoye obozreniye [New Literary Review], (4): 88-95. 